\title{
PRODUTOS DE TRANSFORMAÇÕES DE FASES OBTIDOS SOBRE DISTINTAS CONDIÇÕES DE RESFRIAMENTO EM AÇO BAIXO CARBONO COM MICROADIÇÃO DE MOLIBDÊNIO*
}

\section{Resumo}

\author{
Ana Carolina Abrantes de Souza ${ }^{1}$ \\ Andersan dos Santos Paula ${ }^{2}$ \\ Julio Henrique Pimentel Medrano ${ }^{3}$ \\ Saulo Brinco Diniz ${ }^{4}$ \\ Monica Aline Magalhães Gurge/ ${ }^{5}$
}

O objetivo deste trabalho foi a obtenção de microestruturas diferenciadas, em um aço baixo carbono com microadição de Molibdênio e Nióbio laminado a quente, após submetê-lo a diferentes meios de resfriamento antes e após a temperatura de interrupção de $600^{\circ} \mathrm{C}$ (que simulava a temperatura de bobinamento). A evolução microestrutural e mecânica foi avaliada com o auxílio de técnicas de microscopia óptica e microscopia eletrônica de varredura, testes de dureza Vickers e tração uniaxial, somado a determinação das temperaturas de transformação de fase em um analisador termomecânico (TMA). De acordo com os resultados, meios de resfriamentos mais severos foram mais efetivos em proporcionar um aumento da resistência mecânica associado a decréscimo da ductilidade pela formação de fases mais dura e aumento da acicularidade da ferrita.

Palavras-chave: Aço baixo-carbono; Molibdênio; Laminado a quente; Temperatura de bobinamento.

\section{PHASE TRANSFORMATION PRODUCTS OBTAINED BY DIFFERENT COOLING CONDITIONS IN LOW CARBON STEEL WITH MOLYBDENUM MICROADDITION}

\begin{abstract}
The purpose of this work it was obtain different microstructures in low carbon steel hot rolled with Molybdenum and Niobium micro-additions after submitting it to different rates before and after the temperature interruption of $600^{\circ} \mathrm{C}$ (that simulated the coiling temperature). Scanning Electronic Microscopy, Optical Microscopy, Vickers Hardness Tests and Uniaxial Tensile Tests performed the microstructural and mechanical analyses; in addition, the phase transformation temperatures on heating ( $A_{c 1}$ and $A_{c 3}$ ) were determined on a thermomechanical analyser (TMA). According to the results, high initial cooling rates were more effective in promote an increase strength associated with decrease of ductility by formation hardest phases and increased of ferrite accicularity.

Keywords: Low carbon steel; Molybdenum; Hot-rolled; Coiling temperature.

1 Eng. Metalurgista, Siniat S.A. Mineração, Indústria e Comércio, Rio de Janeiro, RJ, Brasil.

2 D.Sc. em Ciências dos Materiais, Eng. Metalurgista, Professora Adjunta, EEIMVR-VMT e PPGEM, UFF, Volta Redonda, RJ, Brasil.

3 M.Sc. em Eng.Mecânica, Eng. Metalurgista, Especialista em Engenharia de Produtos Laminados a Quente, CSN, Volta Redonda, RJ, Brasil.

4 M.Sc. em Eng. Metalúrgica, Eng. Metalurgista, Doutorando em Ciências dos Materiais, IME, Rio de Janeiro - RJ, Brasil. Contato: saulo brinco@hotmail.com.

5 Eng. Metalurgista, Mestranda em Eng. Metalúrgica, PPGEM, UFF, Volta Redonda, RJ, Brasil.
\end{abstract}

* Contribuição técnica ao $51^{\circ}$ Seminário de Laminação - Processos e Produtos Laminados e Revestidos, 28 a 31 de outubro de 2014, Foz do Iguaçu, PR, Brasil. 


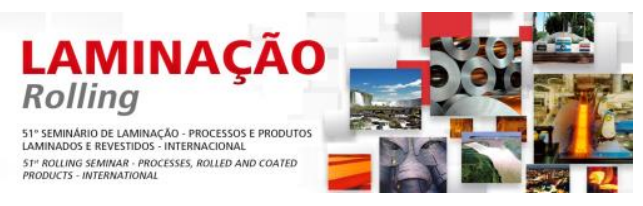

\section{INTRODUÇÃO}

Atualmente, com a crescente demanda e desenvolvimento do setor automobilístico, onde se torna importante melhorar a eficiência no consumo de energia dos veículos, mantendo os custos de fabricação, pode-se observar que as buscas por materiais que sejam ao mesmo tempo leves e possuam altas resistências mecânicas aumenta a cada dia. Sendo assim, o uso de aços como os bifásicos ("dual-phase"), "complexphase" e martensíticos têm aumentado significativamente, principalmente neste setor, pois estes aços aliam uma grande resistência mecânica com uma baixa espessura de suas chapas.

Esses aços apresentam uma excelente relação de resistência-tenacidade, onde observa-se como objetivo principal a redução de peso de diversos componentes estruturais, mantendo suas propriedades mecânicas [1]. Aços "dual-phase" são aqueles onde podemos observar uma matriz ferrítica com ilhas de martensita dispersas (para os ferríticos-martensíticos), ou de bainita (para os ferríticosperlíticos) [2], permitindo que o material se deforme e resista bem ao impacto. Enquanto os aços "complex-phase" são normalmente compostos por um conjunto de fases resistentes (perlita, bainita, martensita e austenita retida) coexistindo em conjunto com uma fase plástica como a ferrita [3].

No caso, por exemplo, dos aços "dual-phase", estes podem ser desenvolvidos de diversas formas, como através de Laminação controlada, para caso de laminados a quente, onde o material, após a laminação de acabamento, é submetido a resfriamentos controlados com o objetivo de aumentar a taxa de nucleação da ferrita num momento inicial dentro do campo intercrítico, enriquecendo com elementos de liga a austenita remanescente aumentando assim sua temperabilidade e consequentemente possibilitando a formação de martensita [4]. Outra possibilidade é a formação dentro de linhas de galvanização, onde é realizado um recozimento no campo intercrítico, afim transformar a perlita existente em austenita enriquecido de elementos de ligas e por resfriamento controlado obter ao fim a martensita ou bainita, para os ferríticos-martens íticos ou ferríticos-bainíticos, respectivamente.

Este trabalho está envolvido num cenário de pesquisa onde se avaliou em um estudo paralelo a influência de distintas temperaturas de bobinamento para obtenção de distintas microestruturais em um aço de baixo carbono com microadições de molibdênio e nióbio, na condição laminada a quente [5]. Em contrapartida devido à necessidade de um maior entendimento das microestruturas que podem ser obtidas através de distintas taxas de resfriamento neste aço em estudo, este trabalho atual teve como objetivo conhecer o comportamento deste aço baixo carbono com microadição de molibdênio e nióbio quando submetido, a diferentes meios de resfriamento antes e após (a fim de simular distintas taxas de resfriamento) a interrupção do resfriamento a uma temperatura de $600^{\circ} \mathrm{C}$ (a fim de simular a temperatura de bobinamento). Tal comportamento foi avaliado através de mudanças microestruturais (quantidade e morfologia das fases - microscopia óptica e eletrônica de varredura) e propriedades mecânicas (ensaios de tração uniaxial e de dureza Vickers), no âmbito do trabalho de conclusão de curso de Souza [6].

\section{MATERIAIS E MÉTODOS}

\subsection{Materiais}

Para este estudo foi utilizado um aço baixo carbono com microadição de molibdênio e nióbio, na forma de chapa laminada a quente em escala industrial (laminado com

* Contribuição técnica ao $51^{\circ}$ Seminário de Laminação - Processos e Produtos Laminados e Revestidos, 28 a 31 de outubro de 2014, Foz do Iguaçu, PR, Brasil. 
temperatura acabamento de $929^{\circ} \mathrm{C}$ e temperatura de bobinamento de $640^{\circ} \mathrm{C}$ ) com $3,2 \mathrm{~mm}$ de espessura, doados pela CSN. A Tabela 1 apresenta a sua composição química.

Tabela 1 - Composição química do aço baixo carbono com microadição de molibdênio e nióbio, laminado a quente, em estudo.

\begin{tabular}{|c|c|c|c|c|c|c|c|}
\hline \multicolumn{7}{|c|}{ Elementos (\% em peso) } \\
\hline $\mathbf{C}$ & $\mathbf{M n}$ & $\mathbf{P}$ & $\mathbf{S}$ & $\mathbf{S i}$ & $\mathbf{C u}$ & $\mathbf{N i}$ & $\mathbf{C r}$ \\
\hline 0,082 & 1,606 & 0,016 & 0,008 & 0,005 & 0,014 & 0,009 & 0,020 \\
\hline $\mathbf{M o}$ & $\mathbf{S n}$ & $\mathbf{A l}$ & $\mathbf{N}$ & $\mathbf{T i}$ & $\mathbf{N b}$ & $\mathbf{V}$ & $\mathbf{F e}$ \\
\hline 0,155 & 0,003 & 0,028 & 0,006 & 0,002 & 0,014 & 0,005 & Restante \\
\hline
\end{tabular}

\subsection{MÉTODOS}

As amostras foram extraídas de uma chapa laminada a quente oriunda de uma bobina a quente não decapada. Inicialmente estas amostras foram cortadas na forma de blanks, e posteriormente divididos em pequenas tiras de $300 \mathrm{~mm} \times 25 \mathrm{~mm}$ (DL - direção de laminação x DT - direção transversal) de modo a possibilitar a retiradas de amostras para posterior análise microestrutural e mecânica nas condições de estudo.

De modo a determinar as temperaturas de transformação de fases no aquecimento (Ac1 e $A_{c 3}$ ) do aço em estudo foram realizadas análises com ciclo de aquecimento com a taxa de $5^{\circ} \mathrm{C} / \mathrm{min}$ até $900^{\circ} \mathrm{C}$ de encharque em um sistema de análise termomecânica (TMA) da Shimadzu, TMA-60.

Os tratamentos térmicos realizados neste trabalho foram feitos com o auxílio de dois fornos (forno do tipo Mufla - Fabricante Brasimet). O primeiro forno utilizado foi mantido a uma temperatura de $950^{\circ} \mathrm{C}$ e o segundo forno a uma temperatura inicial de $600^{\circ} \mathrm{C}$. A Tabela 2 mostra a nomenclatura das amostras em estudo de acordo com os tratamentos térmicos realizados.

Tabela 2 - Nomenclatura das amostras em estudo de acordo com os tratamentos térmicos utilizados. $\mathrm{Na}$ tabela "*" indica resfriamento até a temperatura ambiente sem a interrupção a $600^{\circ} \mathrm{C}$.

\begin{tabular}{|c|c|c|c|c|}
\hline & Amostras & $\begin{array}{c}\text { Meio de Resfriamento } \\
\text { Inicial }\end{array}$ & $\begin{array}{l}\text { Temperatura Interrompida } \\
\left({ }^{\circ} \mathrm{C}\right)\end{array}$ & $\begin{array}{c}\text { Meio de Resfriamento } \\
\text { Final }\end{array}$ \\
\hline \multirow{7}{*}{$\begin{array}{l}\text { Condição de } \\
\text { Resfriamento }\end{array}$} & A26F6 & Água a $20^{\circ} \mathrm{C}$ & 600 & Forno a $600^{\circ} \mathrm{C}$ \\
\hline & AR6A2 & $\mathrm{Ar}$ & 600 & Água a $20^{\circ} \mathrm{C}$ \\
\hline & AR-AR & $\mathrm{Ar}$ & * & $\mathrm{Ar}$ \\
\hline & AR6F6 & $\operatorname{Ar}$ & 600 & Forno a $600^{\circ} \mathrm{C}$ \\
\hline & A86A2 & Água a $80^{\circ} \mathrm{C}$ & 600 & Água a $20^{\circ} \mathrm{C}$ \\
\hline & A8-A8 & Água a $80^{\circ} \mathrm{C}$ & * & Água a $80^{\circ} \mathrm{C}$ \\
\hline & A86F6 & Água a $80^{\circ} \mathrm{C}$ & 600 & Forno a $600^{\circ} \mathrm{C}$ \\
\hline
\end{tabular}

Primeiramente a amostra era retirada do forno, e resfriada até a temperatura de $600^{\circ} \mathrm{C}$, com três tipos distintos de meios de resfriamento (ar parado, água a $20^{\circ} \mathrm{C}$ sob agitação ou água a $80^{\circ} \mathrm{C}$ sob agitação), após a interrupção da temperatura de resfriamento das amostras, elas eram resfriadas em um segundo meio de resfriamento (no interior do forno desligado inicialmente a temperatura de $600^{\circ} \mathrm{C}$, em água a $20^{\circ} \mathrm{C}$ e a $80^{\circ} \mathrm{C}$ sob agitação).

Duas amostras foram resfriadas da temperatura de $950^{\circ} \mathrm{C}$ até a temperatura ambiente (sem interrupção a $600^{\circ} \mathrm{C}$ ), nos seguintes meios: ar parado e água a $80^{\circ} \mathrm{C}$ sob agitação.

As amostras em estudo foram embutidas a quente com uma resina fenólica, e submetidas posteriormente a etapa de lixamento e polimento. O lixamento foi

* Contribuição técnica ao $51^{\circ}$ Seminário de Laminação - Processos e Produtos Laminados e Revestidos, 28 a 31 de outubro de 2014, Foz do Iguaçu, PR, Brasil. 


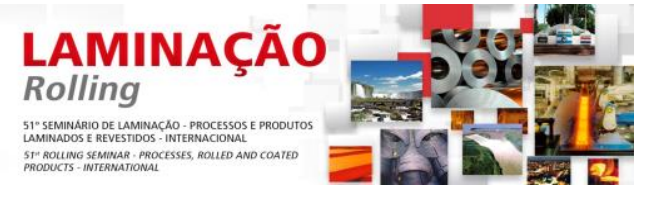

As Figuras de 1 a 8 apresentam as microestruturas para as amostras CR, A26F6, AR6A2, AR-AR, AR6F6, A86A2, A8-A8, A86F6, respectivamente. Para as Figuras com índices (a) e (b) são as microestruturas das amostras em estudo obtidas através de microscopia óptica e microscopia eletrônica de varredura, respectivamente, ambas com o ataque de Nital 3\%, e com índice (c) as condições correspondentes em estudo visualizadas através de microscopia óptica com ataque com o reagente Le Pera. Exceto para a Figura 5 que somente apresenta aspecto microestrutura resultado do ataque com Nital 3\% (a) e Le Pera (b) observado num microscópio óptico.

Com base nas microestruturas observadas por microscopia óptica após ataque com Nital 3\% (Figuras 1a, 2a, 3a, 4a, 5a, 6a, 7a, e 8a), verifica-se que em todas as micrografias das respectivas amostras a presença de grãos de coloração clara, os quais são possivelmente associados a regiões de ferrita pró-eutetóide, no qual todas tiveram aspecto acicurlar ou tendendo para acicular, com exceção das amostras:

- AR-AR (Figura 4a) que teve os grãos de ferrita com morfologia equiaxial homogêneo, devido ao resfriamento a partir de $950^{\circ} \mathrm{C}$ até a temperatura ambiente ter sido realizado ao ar, de maneira mais branda que as demais;

- AR6F6 (Figura 5a), que teve os grãos de coloração clara com morfologia equiaxial tendendo a homogênea, devido ao resfriamento entre $950^{\circ} \mathrm{C}$ e $600^{\circ} \mathrm{C}$ ter sido realizado ao ar, não deslocando de maneira significativa a temperatura de transformação de início da transformação da austenita em ferrita $\left(A_{r 3}\right)$ para valores tão baixas, permitindo que a taxa de nucleação de ferrita não seja tão alta de modo a garantir o seu crescimento e formato final equiaxial.

Nestas microestruturas reveladas por Nital 3\%, estas regiões claras estão delimitadas por contornos em conjunto com regiões de coloração escura, as quais são possivelmente associados a perlita. Na amostra A26F6 (Figura 2a), estas regiões escuras apresentaram frações aparentes diminutas e para as amostras $C R$ (Figura 1a), AR-AR (Figura 4a), AR6F6 (Figura 5a) e A86F6 (Figura 7a), estas regiões escuras tiveram uma fração diminuta e também um com aspecto massivo.

Ao se observar as amostras em estudo, com a microestrutura revelada com Nital $3 \%$, com auxílio do MEV, com um aumento de 5000x, as microestruturas consistiam de regiões de baixo relevo que possivelmente estão associadas a grãos de ferrita pró-eutetóide (indicado pela letra $F$, nas Figuras de 1b, 2b, 3b, 4b, 6b, 7b, e 8b).

Para as amostras A26F6 (Figura 2b), AR-AR (Figura 4b), A8-A8 (Figura 7b) e A86F6 (Figura $8 b$ ) as regiões de alto relevo possivelmente estão associadas a grãos de martensita ou perlita (indicados pelas letras M/P, nas Figuras 2b, 4b, 7b e 8b), pois não foi possível identificar o aspecto lamelar característico da perlita.

Para as amostras AR6A2 (Figura 3b) e A86A2 (Figura 6b) as regiões de alto relevo possivelmente estão associadas a grãos de martensita (indicado pela letra $M$ nas Figuras), e agulhas paralelas adentrando os grãos de ferrita pró-eutetóide, as quais possivelmente estão associadas a feixes de bainita (indicado pela letra B nas Figuras $3 b$ e $6 b)$. Estas agulhas/feixes para a amostra AR6A2 aparentemente são menores do que as da amostra A86A2, o que possivelmente se deve ao resfriamento inicial mais severa na amostra AR6A2 (resfriamento ao ar) do que ao que foi submetido a amostra A86A2 (em água a $80^{\circ} \mathrm{C}$ ), conforme descrito na Tabela 2.

Após repolir as amostras em estudo e realizar o ataque com o reagente Le Pera, as mesmas foram observadas no microscópio óptico, onde pode-se verificar a evidencia de duas regiões com aspecto de coloração diferente para as amostras

* Contribuição técnica ao $51^{\circ}$ Seminário de Laminação - Processos e Produtos Laminados e Revestidos, 28 a 31 de outubro de 2014, Foz do Iguaçu, PR, Brasil. 


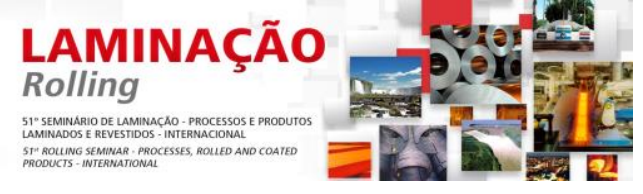

A26F6 (Figura 2c), AR6A2 (Figura 3c), A86A2 (Figura 6c), A8-A8 (Figuras 7a) e A86F6 (Figura 8c).

Para as amostras A26F6 (Figura 2c) e A86F6 (Figura 8c) não foi possível distinguir a presença de regiões mais claras (possivelmente associadas a grãos de martensita) em comparação com regiões de coloração mais escuras (associadas a grãos de ferrita). Já para a amostra A86F6 (Figura 8c) é possível observar a presença de pontos escuros concentrados nas proximidades de região de contornos de grão, no qual possivelmente estão associados a bainita (indicados pela letra B na Figura 8c). A única diferença entre o perfil de resfriamentos destas amostras (A26F6 e A86F6), conforme mostrado na Tabela 6, refere-se ao resfriamento inicial de 950 a $600^{\circ} \mathrm{C}$ ter sido em água a $20^{\circ} \mathrm{C}$ (A26F6) e em água a $80^{\circ} \mathrm{C}$ (A86F6) para posteriormente ambas serem resfriadas ao forno a partir de $600^{\circ} \mathrm{C}$. Sendo assim esta condição inicial de resfriamento não foi severa o suficiente para inibir/reduzir as transformações difusionais (ferrita e perlita) não permitindo assim que uma fração de austenita pudesse se fazer presente no resfriamento final ao forno para formação de alguma martensita em conjunto com a bainita que se fez presente.

As microestruturas das amostras A86A2 (Figura 6c) e A8-A8 (Figura 7c) apresentaram regiões claras circundando as regiões de coloração mais escuras com agulhas entrelaçadas e em alguns pontos adentram as mesmas com formato de agulhas paralelas, e regiões de coloração um pouco mais clara com granulação heterogênea e formato equiaxial. Sendo assim, as regiões escuras podem estar relacionadas a grãos de martensita e a feixes da bainita, e as regiões mais claras associadas a grãos ferríticos com aspecto equiaxial. Porém não foram encontradas evidências de um microconstituinte lamelar correspondente à perlita. A principal diferença na condição de tratamento, conforme mostrado na Tabela 2, que deu origem a estas amostras está no fato de que amostra A8-A8 ter sido resfriada entre $950^{\circ} \mathrm{C}$ e a temperatura ambiente em água a $80^{\circ} \mathrm{C}$, enquanto a amostra $\mathrm{A} 86 \mathrm{~A} 2$ foi resfriada em água a $80^{\circ} \mathrm{C}$ somente entre 950 e $600^{\circ} \mathrm{C}$, pois a partir de $600^{\circ} \mathrm{C}$ a mesma foi transferida para um tanque de resfriamento com água a $20^{\circ} \mathrm{C}$. Fator este que propiciou uma maior severidade no resfriamento abaixo de $600^{\circ} \mathrm{C}$ para amostra A86A2, o que garantiu uma maior fração aparente de martensita formada na mesma (Figura 6b,c) quando comparada a amostra A8-A8 (Figura 7b,c).

Para as amostras CR (Figura 1c), AR-AR (Figura 4c) e AR6F6 (Figura 5b) foi possível verificar a evidencia de três regiões com aspecto de coloração distinta. Os grãos de coloração clara são possivelmente associados a regiões de martensita (indicado pela letra $M$ nas Figuras 1c, 4c e 5b), e as regiões de coloração mais escura possivelmente estão associadas à matriz ferrita (indicado pela letra $F$ nas Figuras 1c, 4c e 5b), e as regiões escuras com aspecto lamelar podem estar associados a grãos de perlita (indicado pela letra $P$ na Figuras 1c, 4c e 5b). Pelo fato destas amostras, como descrito na Tabela 6 , terem sido submetido a condições de resfriamento sem alto grau de severidade garantiu a formação de produtos difusionais (ferrita pró-eutetóide e perlita) de grão mais grosseiro que as demais amostras em estudo, em conjunto com alguma martensita provavelmente devido a microadição de molibdênio que promoveu um aumento na temperabilidade no aço em estudo permitindo a constatação de vestígios de martensita mesmo em taxas de resfriamento pouco severas. Porém com uma fração aparente de martensita mais diminuta nas amostras AR6F6 (Figura 5b) do que nas amostras CR (Figura 1c) e AR-AR (Figura 4c), devido ao resfriamento final ter sido ao forno, em quanto a amostra CR é proveniente do resfriamento no laminar flow e bobinamento, em escala industrial, e a amostra AR-AR totalmente resfriada ao ar.

\footnotetext{
* Contribuição técnica ao $51^{\circ}$ Seminário de Laminação - Processos e Produtos Laminados e Revestidos, 28 a 31 de outubro de 2014, Foz do Iguaçu, PR, Brasil.
} 

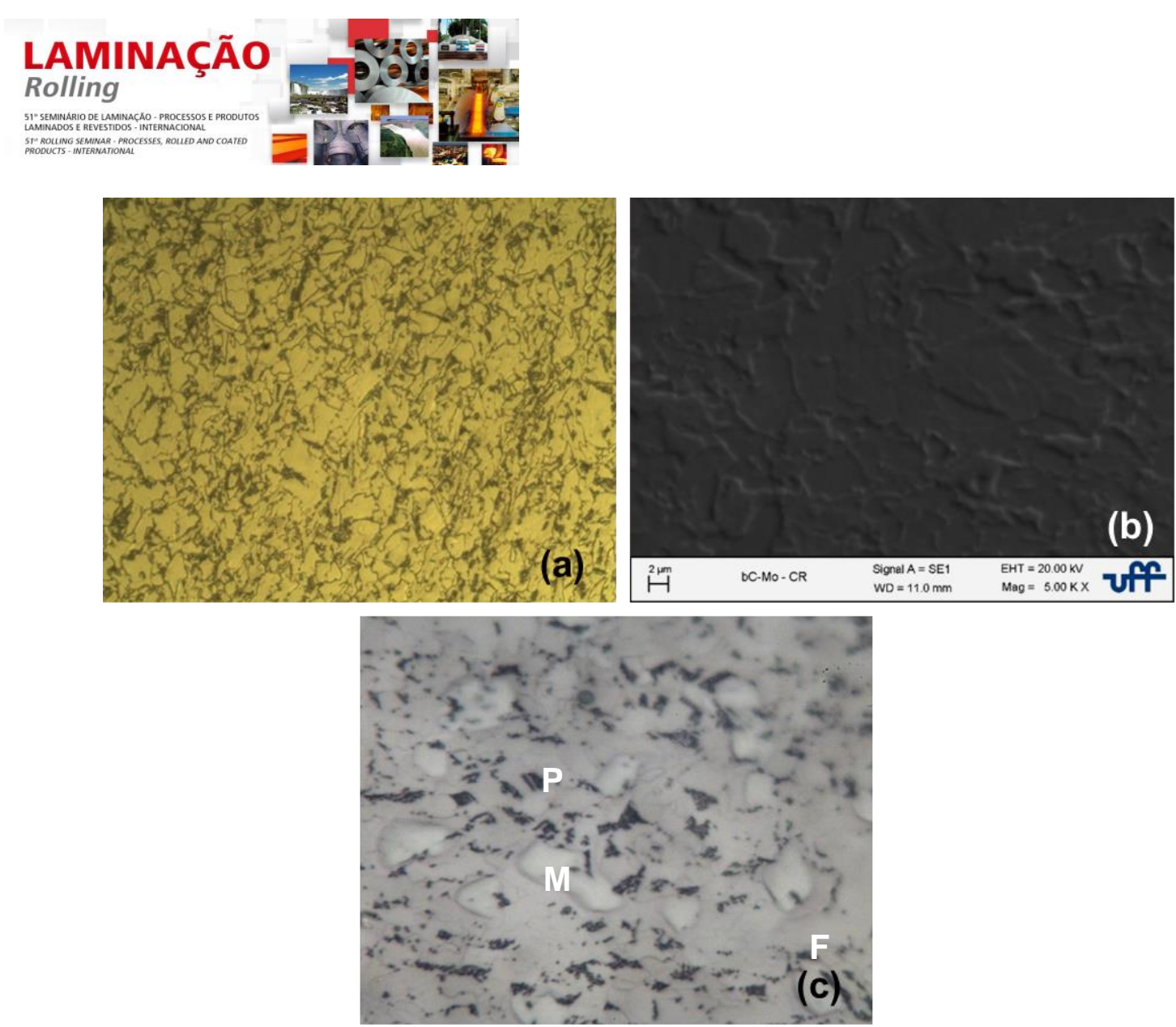

Figura 1 - Aspecto microestrutural da amostra CR, observada por: (a) MO - Nital 3\%, 500x, (b) MEV, Nital 3\%, 5000x, e (c) MO - Le Pera, 1000x. ( $F=$ Ferrita, $M=$ Martensita, $P=$ Perlita).
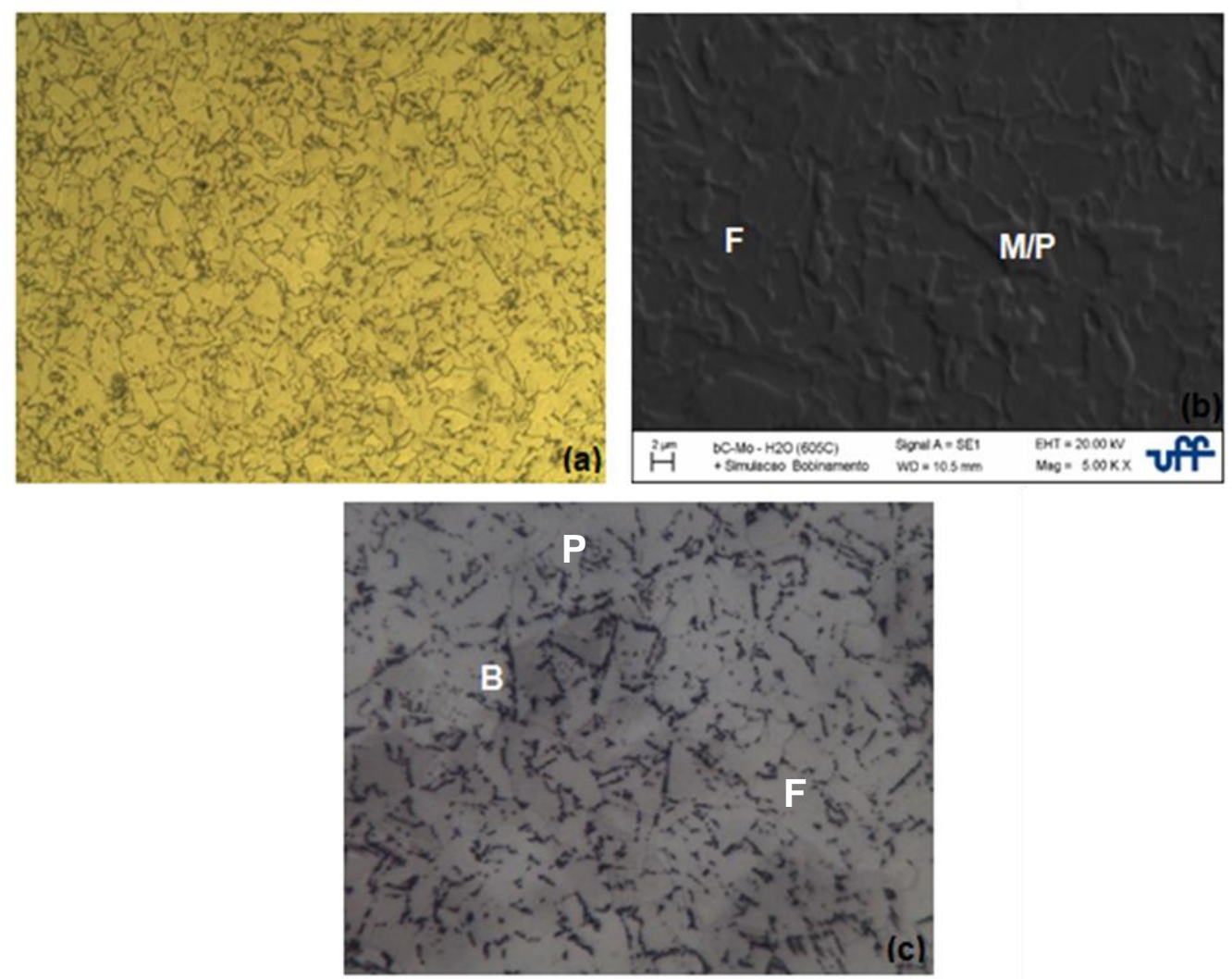

Figura 2 - Aspecto microestrutural da amostra A26F6, observada por (a) MO - Nital 3\%, 500x, (b) MEV, Nital 3\%, 5000x, e (c) MO - Le Pera, 1000x. (F = Ferrita, M/P = Martensita ou Perlita, B = Bainita).

* Contribuição técnica ao $51^{\circ}$ Seminário de Laminação - Processos e Produtos Laminados e Revestidos, 28 a 31 de outubro de 2014, Foz do Iguaçu, PR, Brasil. 

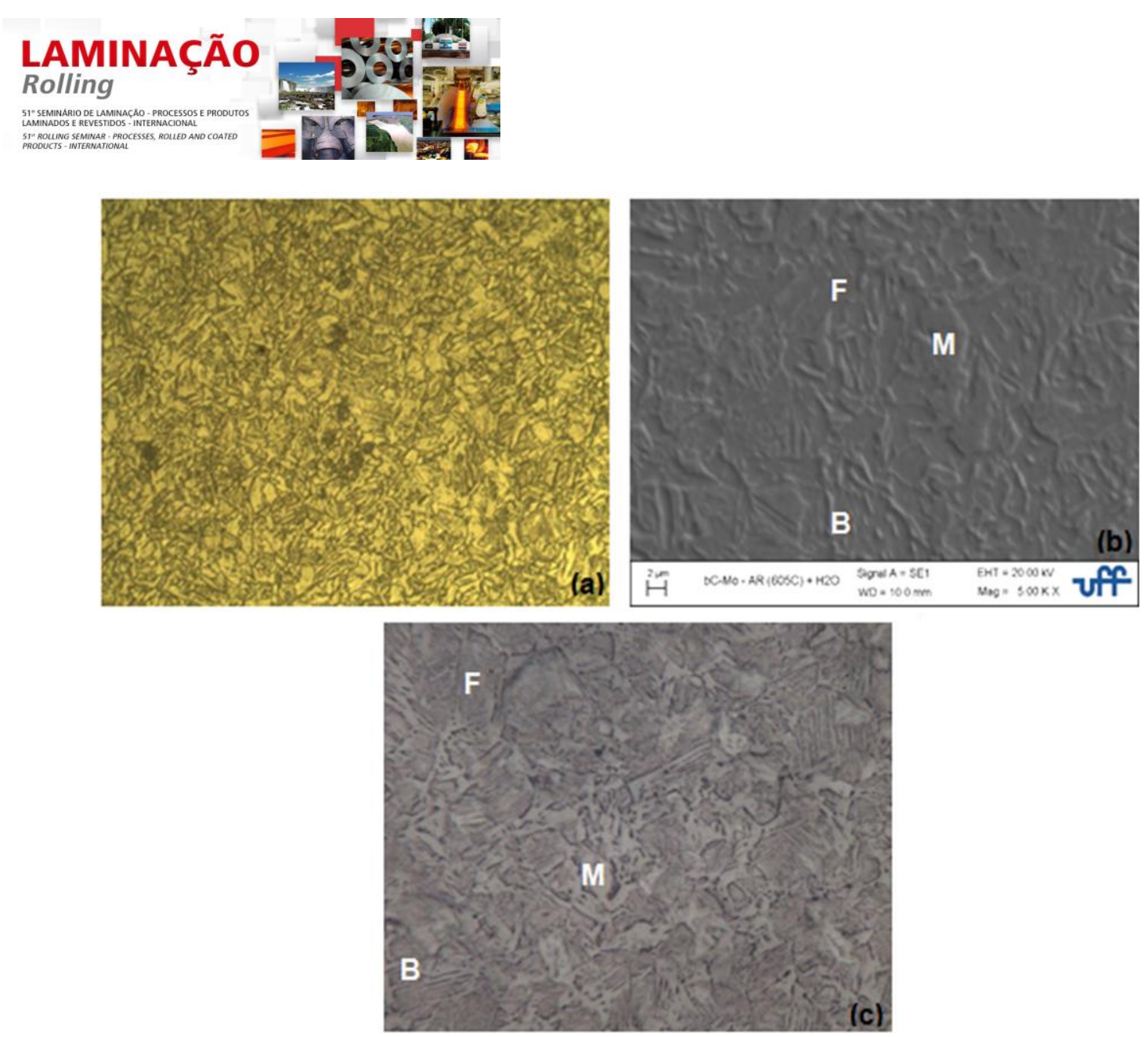

Figura 3 - Aspecto microestrutural da amostra AR6A2, observada por (a) MO - Nital 3\%, 500x, (b) MEV, Nital 3\%, 5000x, e (c) MO - Le Pera, 1000x. ( $F=$ Ferrita, B = Bainita, $M=$ Martensita).
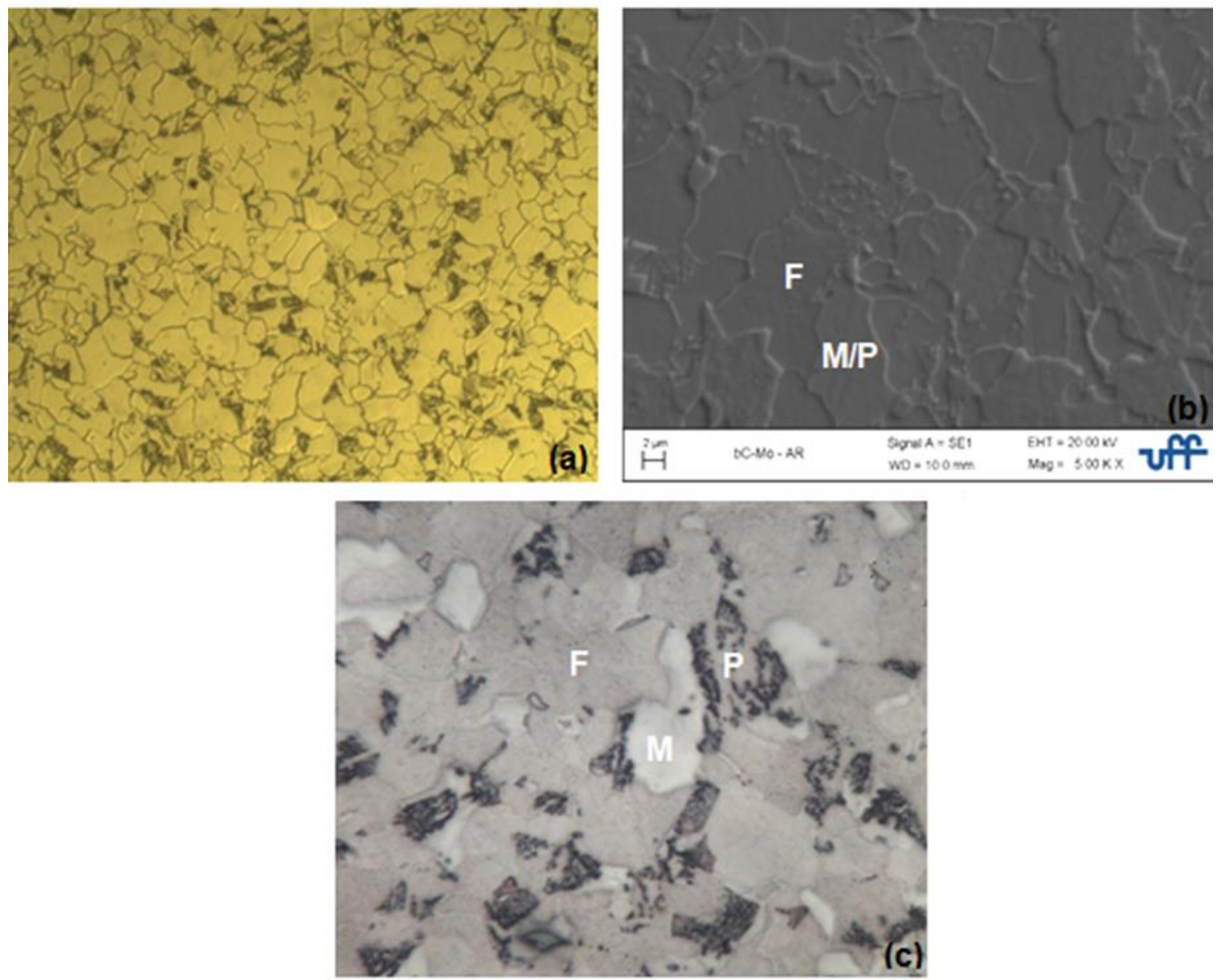

Figura 4 - Aspecto microestrutural da amostra AR-AR, observada por (a) MO - Nital 3\%, 500x, (b) MEV, Nital 3\%, 5000x, e (c) MO - Le Pera, 1000x. ( $F=$ Ferrita, $M=$ Martensita, $P=$ Perlita, $\mathrm{M} / \mathrm{P}=$ Martensita ou Perlita).

* Contribuição técnica ao $51^{\circ}$ Seminário de Laminação - Processos e Produtos Laminados e Revestidos, 28 a 31 de outubro de 2014, Foz do Iguaçu, PR, Brasil. 

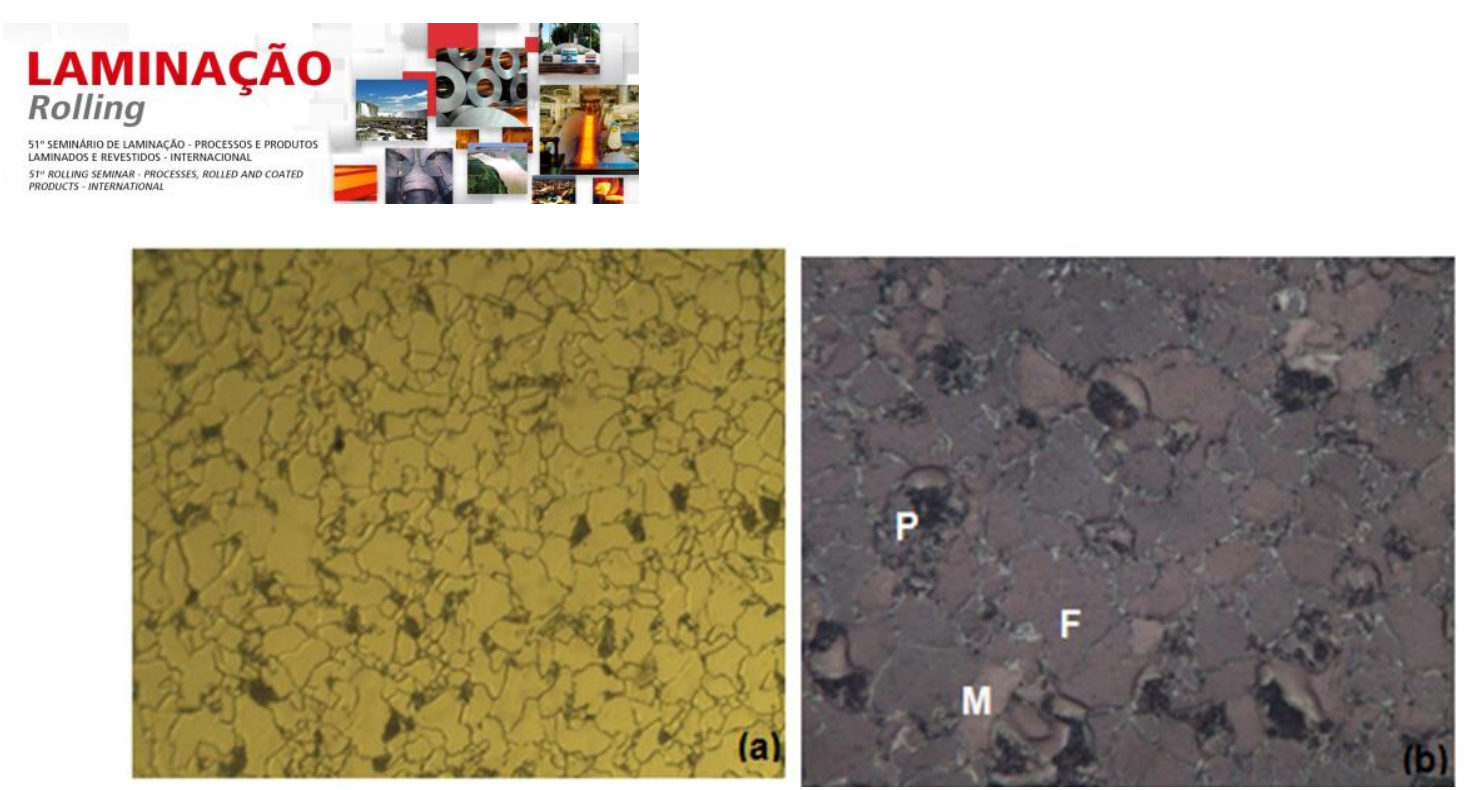

Figura 5 - Aspecto microestrutural da amostra AR6F6, observada por (a) MO - Nital 3\%, 500x, e (b) MO - Le Pera, 1000x. ( $F=$ Ferrita, $M=$ Martensita, $P=$ Perlita).
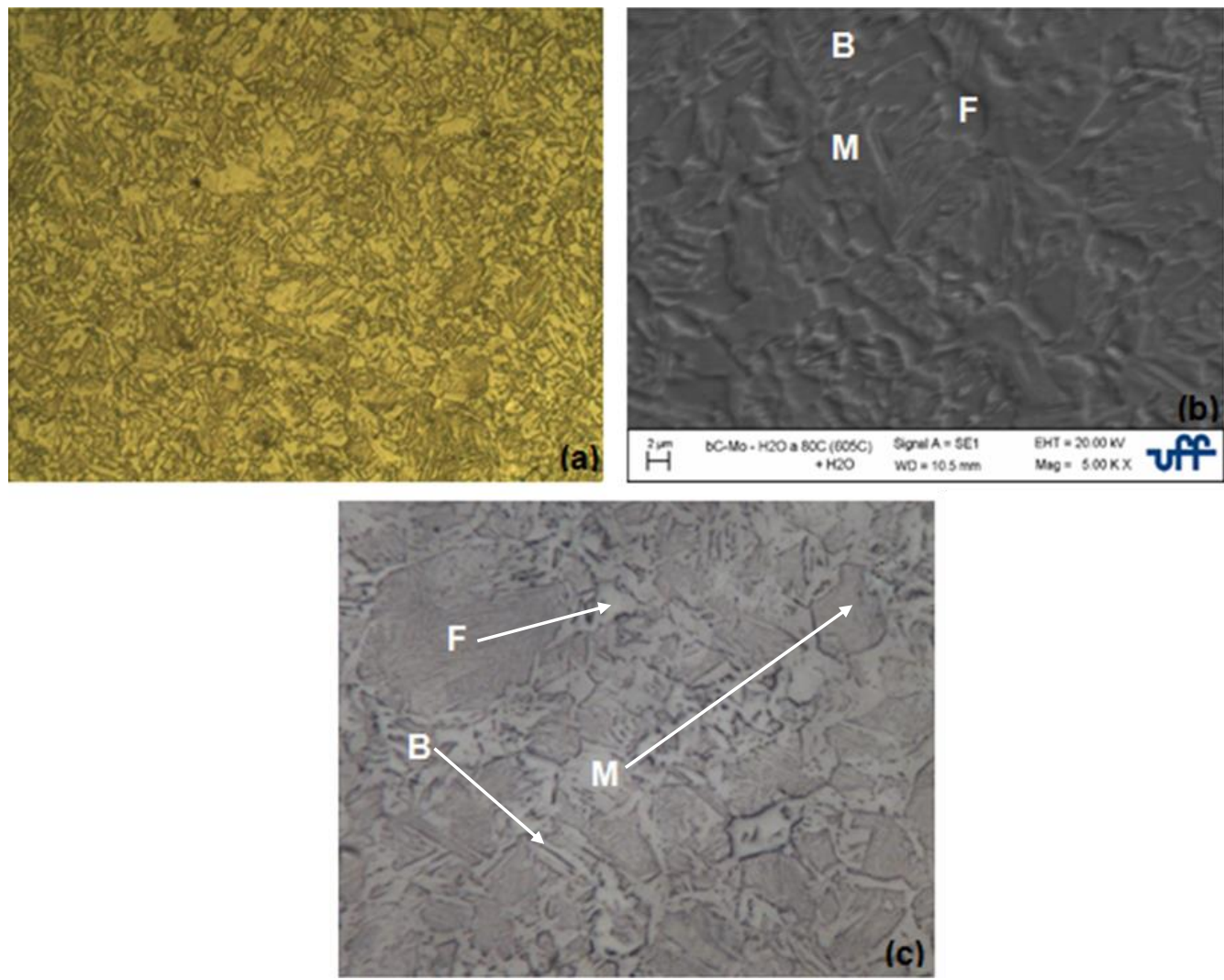

Figura 6 - Aspecto microestrutural da amostra A86A2, observada por (a) MO - Nital 3\%, 500x, (b) MEV, Nital 3\%, 5000x, e (c) MO - Le Pera, 1000x. (F = Ferrita, B = Bainita, M = Martensita).

* Contribuição técnica ao $51^{\circ}$ Seminário de Laminação - Processos e Produtos Laminados e Revestidos, 28 a 31 de outubro de 2014, Foz do Iguaçu, PR, Brasil. 


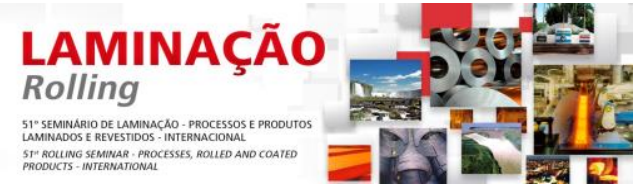

Na Figura 9, verifica-se os valores de dureza Vickers, em função da média e desvio padrão, das amostras em estudo. Enquanto a Tabela 4 apresenta os valores do Limite de Escoamento (LE), Limite de Resistência (LR), Alongamento ( $A L)$ e Razão Elástica (LE/LR), obtidos através do ensaio de tração uniaxial das amostras em estudo.

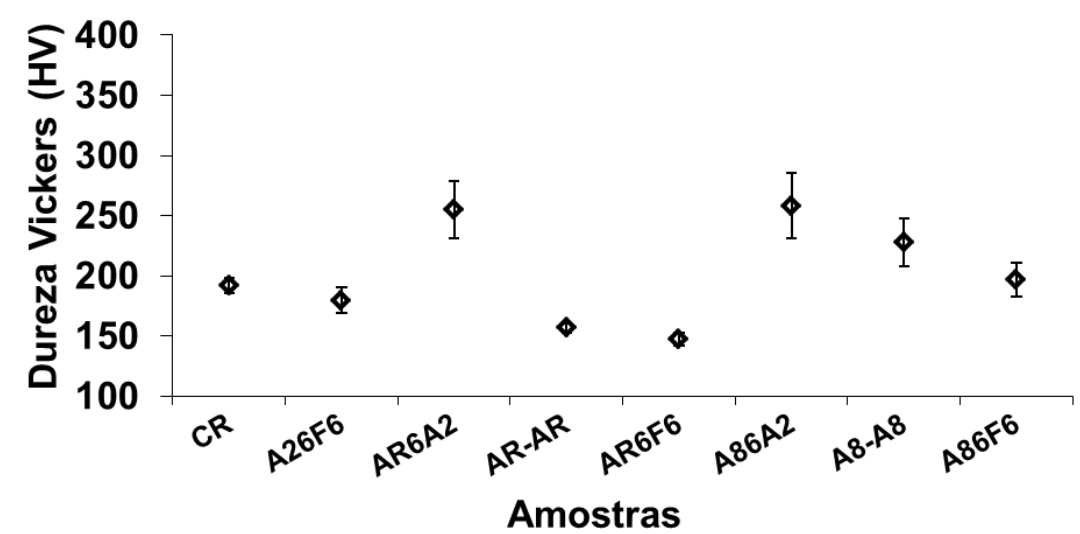

Figura 9 - Evolução de dureza Vickers para as amostras em estudo.

Tabela 4 - Propriedades mecânicas obtidas através o ensaio de tração uniaxial das amostras em estudo.

\begin{tabular}{|c|c|c|c|c|c|c|c|c|}
\hline & CR & A26F6 & AR6A2 & AR-AR & AR6F6 & A86A2 & A8-A8 & A86F6 \\
\hline LE (MPa) & 504,5 & 402 & 512 & 319 & 381 & 508 & 455 & 408 \\
\hline LR (MPa) & 597,5 & 487 & 731 & 496 & 453 & 784 & 701 & 499 \\
\hline AL (\%) & 17,3 & 29,5 & 16,1 & 34,8 & 36 & 13,6 & 19,2 & 26,2 \\
\hline LE/LR & 0,84 & 0,83 & 0,7 & 0,64 & 0,84 & 0,65 & 0,65 & 0,82 \\
\hline
\end{tabular}

Os resultados de dureza Vickers das amostras em estudo apresentados na Figura 9 revelam uma tendência de menor dureza para as amostras que tiveram o meio de resfriamento menos severo (amostra AR-AR e AR6F6).

De acordo com os resultados das propriedades mecânicas provenientes do ensaio de tração (Tabela 4), pode-se verificar em todos os casos uma tendência de incremento no AL e LE/LR e decréscimo no LE e LR com decréscimo da severidade do meio de resfriamento (ao ar e no forno a $600^{\circ} \mathrm{C}$ comparados em água a $20^{\circ} \mathrm{C}$ ) após uma condição de resfriamento acelerada (água a $20^{\circ} \mathrm{C}$ ou água a $80^{\circ} \mathrm{C}$, os quais possivelmente decresceram a temperatura de início de formação da ferrita pró-eutetóide - $A_{r} 3$, verificada para resfriamento ao ar). Este comportamento provavelmente deve-se a maior tendência de formação de constituintes difusionais para taxas de resfriamento contínuo menos acelerado (ao ar) ou condição isotérmica (no forno a $600^{\circ} \mathrm{C}$ ) logo a após a interrupção a $600^{\circ} \mathrm{C}[1]$.

\section{CONCLUSÃO}

De acordo com o estudo realizado pode-se concluir que:

- A utilização de distintos meios de resfriamentos associadas a uma mesma temperatura $\left(600^{\circ} \mathrm{C}\right)$ de mudança do meio de resfriamento apresentaram uma tendência de aumento na resistência mecânica (LE e LR) associado a decréscimo de ductilidade (AL) nas condições de: resfriamentos iniciais e finais acelerados;

- A heterogeneidade microestrutural do produto laminado a quente na condição como recebida para estudo aparentemente influencia na morfologia microestrutural das fases resultantes dos ciclos de resfriamentos estudados;

* Contribuição técnica ao $51^{\circ}$ Seminário de Laminação - Processos e Produtos Laminados e Revestidos, 28 a 31 de outubro de 2014, Foz do Iguaçu, PR, Brasil. 


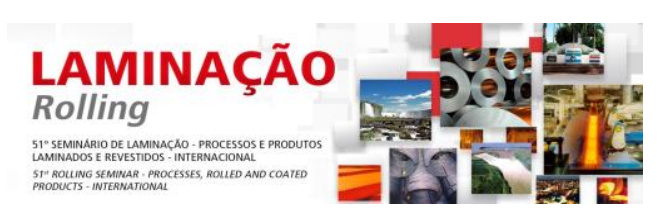

- A microadição de Mo em aços baixo carbono mostra-se eficiente na versatilidade para fabricação de materiais com propriedades e microestruturas distintas pela simples alteração do meio de resfriamento a partir de um produto laminado a quente sem alteração da composição química, mostrando-se assim um candidato a produção de aços de microestrutura elaborada, como por exemplo, "dual-phase" e "complex-phase". Fator este que aumenta o valor agregado dos aços fabricados sem a necessidade da elaboração de uma gama vasta de composições para fabricação de distintos materiais, garantindo um maior controle sobre as etapas de processamento termomecânico.

\section{Agradecimentos}

Os autores agradecem à Companhia Siderúrgica Nacional - CSN pelo fornecimento do material para execução deste trabalho somado aos tratamentos térmicos realizados e ensaios mecânicos de dureza e tração uniaxial. A Escola de Engenharia Industrial Metalúrgica de Volta Redonda (EEIMVR) da UFF, pela disponibilização de equipamentos e consumíveis para preparação das amostras e análise no Microscópio Óptico. Ao Laboratório Multiusuário de Microscopia Eletrônica (LMME) da Universidade Federal Fluminense (UFF) pela utilização do Microscópio Eletrônico de Varredura.

\section{REFERÊNCIAS}

1 Evans JF, Clark MT. AISE Steel Technology, 2002.

2 Gorni AA. et al.. Transformação da Austenita em Aços Microligados com Microestrutura Ferrítica-Bainítica. In: $62^{\circ}$ Congresso Anual da ABM, 2007, Vitória: ABM, 2007, p. 3262 3268.

3 Silva ALC, Mei PR. Aços e Ligas Especiais. Editora Edgard Blücher, 2ª edição, 2006.

4 Ogata PH. et al.. Caracterização Microestrutural de Aço API 5I x65, Austenitizado e Resfriado a Diferentes Taxas de Resfriamento. In: $18^{\circ}$ CONGRESSO BRASILEIRO DE Engenharia e Ciência de Materiais - CBECiMat (2008), 2008, Porto de Galinhas: ABM, 2008.

5 Souza ACA, et al., Influência de Distintas Temperaturas de Bobinamento de um Aço Baixo Carbono com Microadição de Molibdênio, Submetido ao 51ํㅗㄴ Seminário de Laminação - Processos e Produtos Laminados e Revestidos, 2014, Foz do lguaçu: ABM, 2014.

6 Souza ACA. Produtos de Transformação de Fases Obtidos Sobre Distintas Condições de Resfriamento em Aço Baixo Carbono com Microadição de Molibdênio Laminado a Quente. Projeto de conclusão de curso em Engenharia Metalúrgica, Universidade Federal Fluminense, 2011.

* Contribuição técnica ao $51^{\circ}$ Seminário de Laminação - Processos e Produtos Laminados e Revestidos, 28 a 31 de outubro de 2014, Foz do Iguaçu, PR, Brasil. 